\title{
Tocotrienol-Rich Fraction Supplementation Improves the Quality of Oocytes and Maintains Telomere Length in Ovaries from Aging Mice
}

\author{
Norerlyda Hamdan, Nasibah Azme, Mudiana Muhamad, and Nuraliza Abdul Satar \\ Faculty of Medicine, University Teknologi MARA, Sungai Buloh, Selangor, Malaysia \\ Email: \{norerlydahamdan, nasibah.azme\}@gmail.com,mudianamuhamad@yahoo.com, \\ nuraliza064@salam.uitm.edu.my
}

\begin{abstract}
The aim of this study is to determine the effect of tocotrienol-rich fraction (TRF) supplementation on telomere length, telomerase activity and oocytes qualities (morphology and deoxyribonucleic acid damage). Four groups of female mice were used in this study. In Experiment 1: six-weeks-old, young mice were used as negative control (Group A) and eight-months-old aging mice were used as positive control (Group B1). While in Experiment 2: six-month-old aging mice were used; i.e. Group B2 (control group) and Group B3 (supplemented with TRF at the dose of $150 \mathrm{mg} / \mathrm{kg}$ ). Supplementation of TRF was given orally for two months and at the end of the duration, mice will be superovulated and euthanized. The ovaries and oocytes were collected for the determination of telomere length and telomerase activity, as well as assessment of oocytes quality. The results confirmed that aging caused telomere shortening in ovaries and a reduction in oocytes qualities. Conversely, the telomerase activity increased due to the role of telomerase in protecting the mitochondrial function during oxidative stress condition. The TRF supplementation was able to restore the telomere length and telomerase activity as well as decrease the deoxyribonucleic acid (DNA) damage in oocytes. However, TRF supplementation could not improve the oocytes quality in term of morphology. Tocotrienol supplementation potentially delays the consequences of age-related infertility by maintaining the telomere regulation and enhancing the quality of oocytes.
\end{abstract}

Index Terms-reproductive aging, infertility, telomere length, telomerase activity, oocytes quality, DNA damage

\section{INTRODUCTION}

Tocotrienol, a widely used and reputable antioxidant, is known to have a potent role in combating the hazardous effect of free radicals or reactive oxygen species (ROS). Tocotrienol has been previously shown to be able to overcome the detrimental effect of oxidative stress on female reproductive system [1] and subsequently reduced the deoxyribonucleic acid (DNA) damage in embryos [2]. One of the proposed mechanisms of action of tocotrienol is by lowering the plasma levels

Manuscript received February 6, 2017, revised June 30, 2017 of malondialdehyde (MDA) (an oxidative stress biomarker), thus prevent the retardation of embryogenesis and pregnancy failure in nicotine-treated rats [3]. Furthermore, tocotrienol supplementation reversed the effect of oxidative stress on embryonic development in corticosterone-induced oxidative stressed mice [4] and significantly decreased the fetal loss in nicotine-treated mice [5]. These findings clearly indicated that as a powerful antioxidant, tocotrienol possesses great potential in being able to delaying the consequences of aging on reproductive functions.

The reproductive system is particularly susceptible to oxidative stress which causing a progression of various disorders [6] and could then lead to reproductive aging [7]. Reproductive impairment related to oxidative stress contributes to a reduction in the quality in oocytes and increment in embryo fragmentation due to DNA damage [8-10]. An organism's DNA confers a lifetime protection of its genetic material. However, in correspondence with the aging process, the build-up of DNA damage that beyond the cellular repair mechanism will eventually lead to apoptosis [11]. Poor quality oocytes will lead to a decline in the rate of fertilization and a decrease in successful implantation [12]. In these cases, the low fertilization rate could be responsible for a decrease in fertility potential both in human and animals.

Oxidative stress accelerates telomere shortening [13], decreases telomerase activity [14] and oocytes quality, thus resulting in impaired reproductive functions [15]. Telomeres positioned at the end of chromosome and consist of TTAGGG repeats structure [16]. Telomere and its associated proteins (telomeric repeat-binding factor 1 (TRF1/Terf1), telomeric repeat-binding factor 2 (TRF2/ Terf1), protection of telomeres 1 (POT1), TRF1 interacting nuclear protein 2 (TIN2/Tinf2), repressor activator protein 1 (RAP1) plus POT1 and TIN2 interacting protein (TTP1)) defend the chromosome end from breakage to avoid the DNA material from vanishing [17]. Interestingly, mouse cells have two POT1 genes, POT1a and POT1b. Both of these POT1 proteins are associated with telomeres that have a comparable sequence and domain structures [18, 19]. Without telomere associated proteins the TTAGGG repeats will 
be identified as DNA damage and will be inappropriately processed by the DNA repair mechanism $[17,20]$.

Telomerase and its core subunits (telomerase RNA component (TERC) and telomerase reverse transcriptase (TERT)) [21] are important for the lengthening and the maintenance of telomere by the addition of the TTAGGG repeats at the end of chromosome [22]. When the telomerase is absent, the telomere becomes shorter and breaks the chromosomal end, which will eventually result in cells senescence and aging [23]. The shorter telomere will lead to telomere dysfunction as well as faulty reproductive processes (e.g. meiosis, fertilization and embryonic development), resulting in a decrease in fertility and reproductive malfunction. Due to ROSinduced damage, the telomeres become shorter, along with an increase in oocytes and embryos apoptosis, which consequently stops their further development [8].

One of the consequences of aging-induced oxidative stress is infertility in the female. Infertility has become a concern in developing countries with approximately 72.4 million couples experiencing infertility worldwide [24]. Among the causes of infertility include impairment of reproductive function, environmental factors, incidence of reproductive illness and biological aging [25]. For most career women, age becomes a foremost factor in causing decreased fertility due to the postponement of childbearing.

Therefore, the present study was designed to determine whether tocotrienol supplementation could overcome the effect of aging on the quality of oocytes and telomere as well as telomerase gene expression in ovaries. We propose that the antioxidant properties of tocotrienol reduce the ROS levels and delays telomere shortening in the ovaries of aging mice.

\section{MATERIALS AND METHODS}

\section{A. Materials}

The compounds used in this study include Tocopherolstripped corn oil (MP Biomedicals, USA) and Tocotrienol-rich fraction palm oil (Sime Darby Bioganic Sdn. Bhd., Malaysia). Tocotrienol-rich fraction palm oil per $100 \mathrm{~g}$ contained: $\alpha$-tocotrienol $(27.3 \%), \beta$-tocotrienol (3.3\%), $\gamma$-tocotrienol (35.5\%), $\delta$-tocotrienol (10.4\%) and $\alpha$-tocopherol $(23.4 \%)$. The TRF compound was diluted with tocopherol-stripped corn oil [3] to gain the desired concentration of 90,120 and $150 \mathrm{mg} / \mathrm{kg}$ body weight. This dosage was selected based on our TRF dosedependent studies [26, 27].

\section{B. Experimental Animals}

Female Mus Musculus mice (aged 6 weeks, 6 months and 8 months) were used for experiments with eight mice in every group. Animals were provided with food pellets and water ad libitum on a daily basis and housed at $27^{\circ} \mathrm{C}$ in 12 hours light-dark cycles. The mice were supplemented with TRF at a dose of $150 \mathrm{mg} / \mathrm{kg}$ body weight $(\mathrm{BW})$ orally for two months, using oral-gavage (20 G straight feeding needle with smooth ball on the tip (Kent Scientific Corporation, USA) [4]). The TRF dose selected was the optimum dose based on the time- and dose-dependent effect of TRF on the quality of embryos $[26,27]$ The experimental procedures were in strict accordance with regulations prescribed by the Research Committee on the Ethical Use of Animals (UiTM Care: 98/2015).

\section{Collection of Oocytes}

After two months of TRF supplementation, the animals were superovulated intraperitoneally with $5 \mathrm{IU}$ of pregnant mare serum gonadotropin (PMSG) (Sigma, Aldrich), followed by $5 \mathrm{IU}$ of human chorionic gonadotropin (hCG) (Sigma, Aldrich) 48 hours later [28]. Subsequently, 14 hour after hCG injection, the mice were euthanized and oocytes were collected by tearing the ampullae from oviduct. The cumulus cells from oocytes were removed using hyaluronidase (Sigma, Aldrich) and oocytes were kept in M2 medium until further analysis. M2 medium is a modified Krebs-Ringer solution with some of the bicarbonate substituted with HEPES buffer in order to maintain the correct $\mathrm{pH}$ and this medium is used for collecting and keeping the embryos.

\section{Analysis of Telomere and Telomerase Genes Expression}

The ribonucleic acid (RNA) from the ovaries was extracted using RNeasy Plus Midi Universal Kit (Qiagen, USA). The quantity of RNA was measured using Nanodrop ND-1000 (Thermo Scientific, USA) to get the sufficient amount of RNA according to manufacturer's protocol for PCR Array. The gene expression of telomere and telomerase genes was measured using $\mathrm{RT}^{2}$ Profiler Polymerase Chain Reaction (PCR) Arrays (Qiagen, USA) and performed by CFX 96 real-time PCR detection system (Bio-Rad).

\section{E. Sample and Statistical Analysis}

Data were analysed using Statistical Package for Social Science (SPSS). The data for the quality of oocytes (morphology and DNA damage) were analysed using Chi-square test. Data analysis for telomere length and telomerase activity was calculated using gene study application in CFX 96 qPCR software. The relative normalised expression of telomere and telomerase genes were evaluated using student t-test and one-way ANOVA.

\section{RESULTS AND DISCUSSIONS}

\section{A. Deleterious Effect of Aging on the Quality of Oocytes, Telomere Length and Telomerase Activity}

In this study, the qualities of oocytes were determined by the percentage of normal morphology and DNA damage in oocytes (Fig. 1). The quality of oocytes can also be evaluated by other parameters i.e. changes in morphology (ooplasm, polar body, zona pellucida, follicle ovaries, meiotic spindle) and cellular (mitochondria, G6PDH, calcium, apoptosis, oxidative stress marker) as well as molecular predictors (profiling and gene expression) [29]. The percentage of normal morphology of oocytes were significantly reduced $(p<0.05)$ and the fragmented oocytes were significantly increased $(p<0.05)$ in the aging group (Group B1) when 
compared to the young group (Group A) respectively. Previous studies have demonstrated that age-related oxidative stress contributes to impairment in oocytes quality [30]. With increasing age, genetic mutations can cause cells to degenerate and break down [11]. We found that the percentage of DNA damage in oocytes were significantly higher $(\mathrm{p}<0.05)$ in aging group (Group B1) when compared to young group (Group A). These results are in line with another study that reported DNA damage accumulation occurs with increasing age [31]. Similarly, mice exposed to oxidative stress condition showed elevated DNA damage in the embryos and a decrease in the quality and percentage of embryonic development [2].

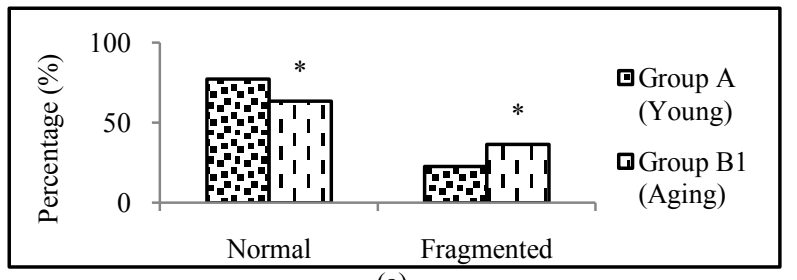

(a)

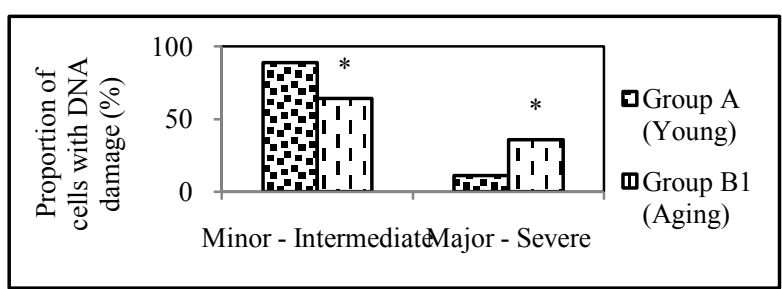

(b)

Figure 1. The effect of aging on the quality of oocytes: (a) percentage of normal morphology and (b) percentage of DNA damage

Age-related infertility caused by the oxidative stress also directly affects the telomere length and speed up its erosion or shortening of telomere [13]. The telomere acts as an indicator for the biological clock of organism's lifespan. The telomere also protects the chromosomal end from breakage to avoid genetic material from dispersing during cell proliferation [32]. Telomere erosion caused impairment in meiosis, fertilization, embryo development, consequently leading to sterility and reproductive malfunction. Furthermore, the shortening of telomeres triggered apoptosis in oocytes and embryos, leading to development retardation [8]. The findings of Experiment 1 indicate strong evidence of telomere shortening when the telomeric genes (Terf1, Terf2, Pot1a and Tinf2) were highly expressed in aging group $(\mathrm{p}<0.001, \mathrm{p}<0.01)$ (Group B1) as compared to young group (Group A) (Fig. 2 ). The overexpression of telomere shelterin genes results in the progressive shortening of telomere length [17, 33, 34]. Conversely, there is no significant different in TPP1 gene expression between aging (Group B1) and the young group (Group A). Our finding is in line with that of Hockemeyer et al. (2006) who reported the HCT116TPP1 cells demonstrate a significant telomere extension when compared to control cells. This indicates that TPP1 may act as a positive regulator for telomeres. On the other hand, in human fibrosarcoma HTC75, TPP1 expression exerts no significant effect on the telomere length. The dissimilarity among these results may possibly be due to the distinct use of cell lines [18]. On the contrary, Rapla gene expression is significantly lower $(\mathrm{p}<0.001)$ in aging group (Group B1) as compared to young group (Group A) (Fig. 2). In an earlier study, Martinez et al. (2010) found that the absence of RAP1 in immortalized mouse embryonic fibroblast (MEFs) did not produce any striking effect on the telomere length. However, they showed 26 percent of reduction in the mean of telomere length in mouse epidermis [35].

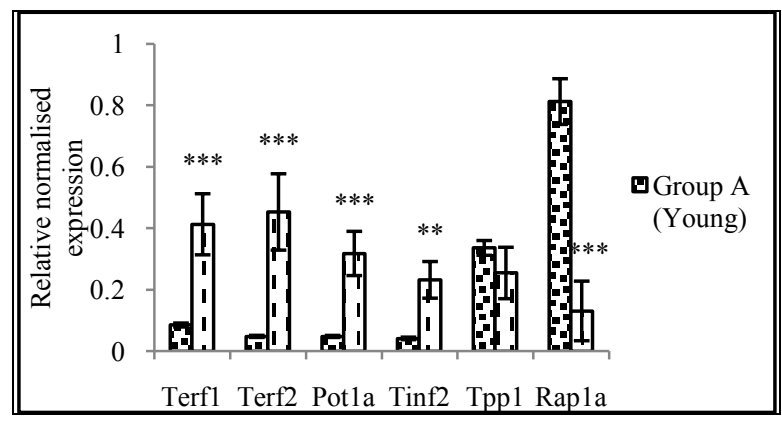

Figure 2. The effect of aging on the three important shelterin genes (Terf1, Terf2 and Pot1a) that associated with the other three other shelterin genes (TIN2, TPP1 and Rap1) in regulating the telomere length

Telomerase is an enzyme that is responsible to lengthen the telomeres. Essentially, telomerase contained two units, telomerase reverse transcriptase (TERT) and telomerase RNA component (TERC) [21]. While the telomere length tends to shorten, the telomerase is responsible to maintain the telomere length. The finding in fig. 3 shows that the aging group (Group B1) have a significantly higher $(\mathrm{p}<0.001)$ TERT gene expression than young group (Group A). Nevertheless, results of this study were not able to show that the reduction of telomerase activity is critical to accomplish preferential extension of short telomeres and telomere length maintenance [36]. An earlier study reported that mice with overexpression of telomerase are prone to the buildup of tumors [37]. On the other hand, telomerase activity was reported not to counteract telomeres shortening but instead protect the mitochondrial function under oxidative stress condition [38].

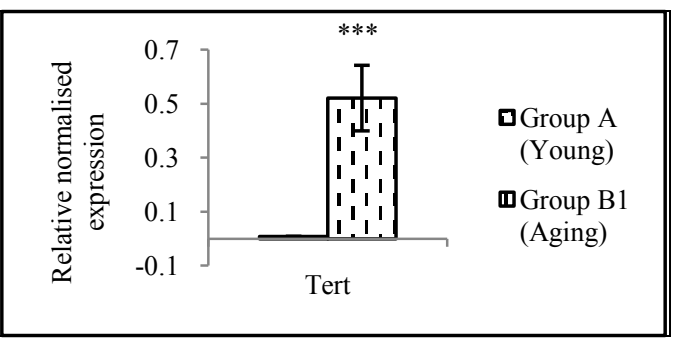

Figure 3. The effect of aging on the telomerase genes that regulate the telomerase activity

\section{B. Protective Effect of Tocotrienol Supplementation on the Quality of Oocytes, Telomere Length, and Telomerase Activity}

Tocotrienol has been proven to exert a protective antioxidant effect against free radical damage in 
reproductive system. Kamsani et al. (2013) reported that tocotrienol decreased fetal loss in nicotine-treated mice [5]. Moreover, another study reported that TRF was able to improve the quality of impaired mouse embryonic development induced by excessive corticosterone [4].

In this study, the quality of oocytes was determined by the percentage of normal morphology and percentage of DNA damage in aging female mice supplemented with the optimum dose of TRF $(150 \mathrm{mg} / \mathrm{kg})$ that was obtained from previous study [27]. Aging caused a significant reduction on the quality of oocytes (Fig. 1). However, TRF supplementation could not recover the quantity of oocytes retrieved from aging mice towards those that was retrieved from young mice. As shown in fig. 4, no significant different were noted in the percentage of normal and fragmented oocytes between vehicle control (Group B2) and TRF-supplemented group (Group B3). Interestingly, the percentage of DNA damage in oocytes from TRF-supplemented group (Group B3) was a significantly lower $(\mathrm{p}<0.05)$ as compared to control group (Group B2). It is proposed that tocotrienol reduces oxidative stress and thus potentially reduces DNA damage, which eventually protects the quality of oocytes in aging mice.

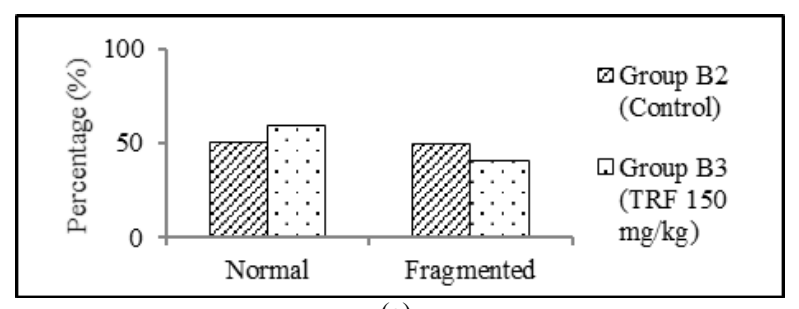

(a)

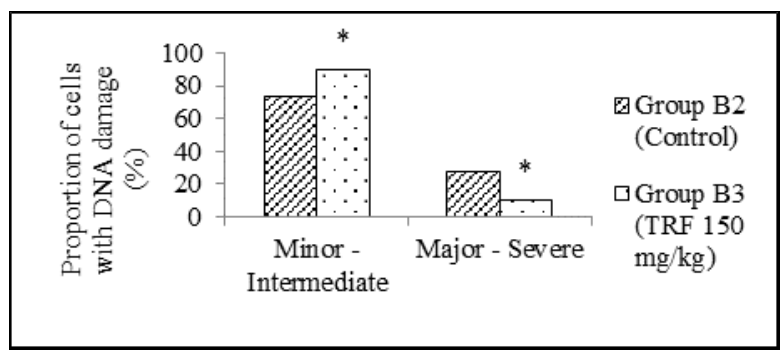

(b)

Figure 4. The effect of TRF supplementation on the quality of oocytes: a) percentage of normal morphology b) percentage of DNA

The decline in telomere length is considered as a hallmark of aging [39]. Individuals with longer telomeres have decreased mortality rate compared to those with shorter telomeres [40]. Thus, it is important to maintain the optimum telomere length in order to delay the consequences of aging. In Experiment 2, TRF supplementation in aging mice (Group B3) lengthen the telomere while the expression of telomeric genes (Terf1, Terf2, Pot1a, Tinf2, Tpp1 and Rap1a) were significantly decreased $(\mathrm{p}<0.001, \mathrm{p}<0.01)$ when compared to the control group (Group B2) (Fig. 5). Inhibition of telomeric genes will result in telomere elongation [17, 18, 41-44].

Telomerase activity was assessed by the TERT gene expressions (Fig. 6). The TRF-supplemented group (Group B3) showed a significant reduction $(p<0.001)$ in
TERT gene expression as compared to the control group (Group B2). It is proposed that tocotrienol supplementation reinstated the telomere length maintenance and sustains the role of TERT in defending mitochondrial function [38] from free radicals-induced oxidative damage.

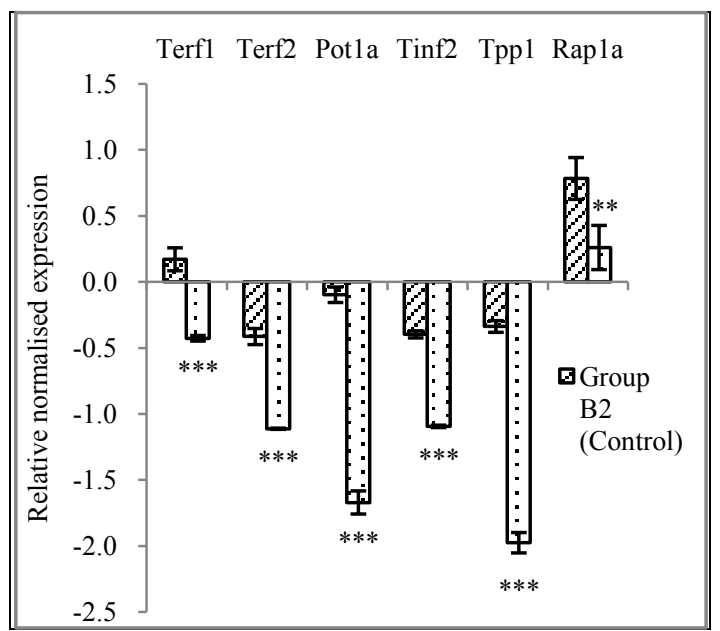

Figure 5. The effect of TRF supplementation on the three important shelterin genes (Terf1, Terf 2 and Pot1a) that associated with the other three other shelterin genes (TIN2, TPP1 and Rap1) in regulating the telomere length

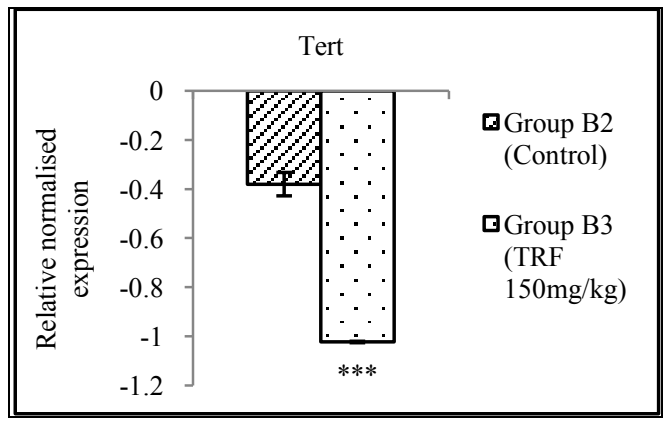

Figure 6. The effect of TRF supplementation on the telomerase genes that regulate the telomerase activity

\section{CONCLUSION}

In conclusion, tocotrienol supplementation improves the quality of oocytes in aging mice by lowering the percentage of DNA damage. It is suggested that tocotrienol exerts an anti-aging effect on the ovaries by maintaining the telomere length and telomerase activity. The preservation of the production of good quality oocytes by tocotrienol will potentially facilitate higher rates of fertilization, ensure the success of implantation and in the end, improve fertility.

\section{ACKNOWLEDGMENT}

This work was supported by the Fundamental Research Grant Scheme, FRGS (600-RMI/FRGS 5/3 (34/2013)). The authors acknowledge the research facilities provided by the Laboratory Animal Care Unit (LACU), Universiti Teknologi MARA (UiTM) and the Institute of Medical Molecular Biotechnology (IMMB), UiTM. 


\section{REFERENCES}

[1] A. Nasibah, M. H. Rajikin, M. Nor-Ashikin, and A. S. Nuraliza, "Effects of tocotrienol supplementation on pregnancy outcome in mice subjected to maternal corticosterone administration," Journal Oil Palm Resesarch, vol. 24, pp. 1550-1558, 2012.

[2] Z. A. Shahidee, A. Nasibah, I. Effendi, R. A. F. Gabriele, and A. S. Nuraliza, "Tocotrienol reverses the corticosterone-induced oxidative stress effect on the quality of mouse embryo," in Proc. AKEPT 2nd Global Annual Young Researchers Conference and Exhibition, 2012.

[3] N. Mokhtar, M. Rajikin, and Z. Zakaria, "Role of tocotrienol-rich palm vitamin $\mathrm{E}$ on pregnancy and preim plantation embryos in nicotine-treated rats," Biomedical Research, vol. 19, pp. 181-184, 2008 .

[4] A. Nasibah, M. Rajikin, M. Nor-Ashikin, and A. S. Nuraliza, "Tocotrienol improves the quality of impaired mouse embryos induced by corticosterone," in Proc. IEEE Colloqium on Humanities, Science and Engineering (CHUSER), 2012.

[5] Y. S. Kamsani, M. Rajikin, M. Nor-Ashikin, A. S. Nuraliza, and A. Chatterjee, "Nicotine-induced cessation of embryonic development is reversed by $\gamma$-tocotrienol in mice," Medical Science Monitor Basic Research, vol. 19, pp. 87-92, 2013.

[6] D. R. Riddle, C. Gemma, J. Vila, A. Bachstetter, and P. C. Bickford, Oxidative Stress and the Aging Brain: From Theory to Prevention, Boca Raton (FL): CRC Press/Taylor and Francis, 2007.

[7] A. Agarwal, A. Aponte-Mellado, B. Premkumar, A. Shaman, and S. Gupta, "The effects of oxidative stress on female reproduction: a review," Reproductive Biology Endocrinology, vol. 10, no. 1, p. 49, 2012.

[8] J. Liu, et al., "Delay in oocyte aging in mice by the antioxidant Nacetyl-L-cysteine (NAC)," Human Reproduction, vol. 27, no. 5, pp. 1411-1420, 2012.

[9] Z. A. Shahidee, A. Nasibah, and A. S. Nuraliza, "The damaging effects of corticosterone on the developing mouse embryos," Malaysian Journal Microscopy, vol. 9, pp. 117-122, 2013.

[10] H. W. Yang, K. J. Hwang, H. C. Kwon, H. S. Kim, K. W. Choi, and K. S. Oh, "Detection of reactive oxygen species (ROS) and apoptosis in human fragmented embryos," Human Reproduction, vol. 13, no. 4, pp. 998-1002, 1998.

[11] K. Jin, "Modern biological theories of aging," Aging and Disease, vol. 1, no. 2, pp. 72-74, 2010.

[12] S. K. Gupta, et al., "Mammalian zona pellucida glycoproteins: structure and function during fertilization," Cell Tissue Research, vol. 349, no. 3, pp. 665-678, 2012.

[13] T. V. Zglinicki, "Oxidative stress shortens telomeres," Trends in Biochemical Sciences, vol. 27, no. 7, pp. 339-344, 2002.

[14] M. A. Blasco, "Telomeres and human disease: Aageing, cancer and beyond," Nature Reviews Genetics, vol. 6, pp. 611-622, 2005.

[15] N. Danilovich and M. R. Sairam, "Recent female mouse models displaying advanced reproductive aging," Experimantal Gerontology, vol. 41, no. 2, pp. 117-122, 2006.

[16] E. H. Blackburn, "Telomere states and cell fates," Nature, vol 408, no. 6808, pp. 53-56, 2000.

[17] T. De Lange, "Shelterin: The protein complex that shapes and safeguards human telomeres," Genes and Development, vol. 19, no. 18 , pp. $2100-2110,2005$.

[18] D. Hockemeyer, J. P. Daniels, H. Takai, and T. De Lange, "Recent expansion of the telomeric complex in rodents: Two distinct POT1 proteins protect mouse telomeres," Cell, vol. 126, no. 1, pp. 63-77, 2006.

[19] L. Wu, et al., "Pot1 deficiency initiates DNA damage checkpoint activation and aberrant homologous recombination at telomeres," Cell, vol. 126, no. 1, pp. 49-62, 2006.

[20] P. Martínez and M. A. Blasco, "Telomeric and extra-telomeric roles for telomerase and the telomere-binding proteins," Nature Reviews Cancer, vol. 11, no. 3, pp. 161-176, 2011.

[21] E. H. Blackburn, "Switching and signaling at the telomere," Cell, vol. 106 , no. 6 , pp. 661-673, 2001

[22] W. Fu, J. G. Begley, M. W. Killen, and M. P. Mattson, "Antiapoptotic role of telomerase in pheochromocytoma cells," Journal Biological Chemistry, vol. 274, no. 11, pp. 7264-7271, 1999.
[23] M. A. Blasco, et al., "Telomere shortening and tumor formation by mouse cells lacking telomerase RNA," Cell, vol. 91, no. 1, pp. 25-34, 1997.

[24] J. Boivin, L. Bunting, J. A. Collins, and K. G. Nygren, "International estimates of infertility prevalence and treatmentseeking: Potential need and demand for infertility medical care," Human Reproduction, vol. 22, no. 6, pp. 1506-1512, 2007.

[25] J. Menken, J. Trussell, and U. Larsen, "Age and infertility," Science, vol. 233, no. 4771, pp. 1389-1394, 1986.

[26] A. K. Saidatul, A. Nasibah, N. Y. Esa, and A. S. Nuraliza, "Timedependant effect of tocotrienol supplementation on the quality of aging mouse embryo," Malaysian Journal Microscopy, vol. 10, pp. 6-12, 2014.

[27] H. Norerlyda, M. Fathimah, and A. S. Nuraliza, "The effect of tocotrienol supplementation on plasma estradiol levels and quality of embryos in aging mice," Malaysian Journal Microscopy, vol. 11 , pp. 32-38, 2015.

[28] A. Nagy, M. Gertsenstein, K. Vintersten, and R. Behringer, Manipulating the Mouse Embryo: A Laboratory Manual, New York: Cold Spring Harbor Laboratory Press, 2003.

[29] Q. Wang and Q. Y. Sun, "Evaluation of oocyte quality: morphological, cellular and molecular predictors," Reproduction Fertility Development, vol. 19, no. 1, pp. 1-12, 2006.

[30] H. Tamura, et al., "Oxidative stress impairs oocyte quality and melatonin protects oocytes from free radical damage and improves fertilization rate," Journal of Pineal Research, vol. 44, no. 3, pp. 280-287, 2008,

[31] F. P. Miller, A. F. Vandome, and J. McBrewster, DNA Damage Theory of Aging, Alphascript Publishing, 2009.

[32] U. N. Das, "Telomere length and polyunsaturated fatty acids," Nutrition, vol. 30, no. 10, pp. 1218-1221, 2014.

[33] A. Smogorzewska, et al., "Control of human telomere length by TRF1 and TRF2," Molecular Cell Biology, vol. 20, no. 5, pp. 1659-1668, 2000.

[34] S. H. Kim, P. Kaminker, and J. Campisi, "TIN2, a new regulator of telomere length in human cells," Nature Genetics, vol. 23, no. 4 pp. 405-412, 1999.

[35] P. Martinez, et al., "Mammalian Rap1 controls telomere function and gene expression through binding to telomeric and extratelomeric sites," Nature Cell Biology, vol. 12, no. 8, pp. 768$780,2010$.

[36] G. Cristofari and J. Lingner, "Telomere length homeostasis requires that telomerase levels are limiting," EMBO Journal, vol. 25, no. 3, pp. 565-574, 2006.

[37] E. González-Suárez, et al., "Increased epidermal tumors and increased skin wound healing in transgenic mice overexpressing the catalytic subunit of telomerase, mTERT, in basal keratinocytes," EMBO Journal, vol. 20, no. 11, pp. 2619-2630, 2001.

[38] S. Ahmed, et al., "Telomerase does not counteract telomere shortening but protects mitochondrial function under oxidative stress," Jornal of Cell Science, vol. 121, no. 7, pp. 1046-1053, 2008.

[39] C. López-Otín, M. A. Blasco, L. Partridge, M. Serrano, and G. Kroemer, "The hallmarks of aging," Cell, vol. 153, no. 6, pp. 1194-1217, 2013.

[40] R. M. Cawthon, K. R. Smith, E. O'Brien, A. Sivatchenko, and R. A. Kerber, "Association between telomere length in blood and mortality in people aged 60 years or older," The Lancet, vol. 361, no. 9355, pp. 393-295, 2003.

[41] J. R. Donigian and T. De Lange, "The role of the poly (ADPribose) polymerase tankyrase 1 in telomere length control by the TRF1 component of the shelterin complex," Journal of Biological Chemistry, vol. 282, no. 31, pp. 22662-22667, 2007.

[42] H. Xin H, et al., "TPP1 is a homologue of ciliate TEBP-[bgr] and interacts with POT1 to recruit telomerase," Nature, vol. 445, no. 7127, pp. 559-562, 2007.

[43] B. Li and T. De Lange, "Rap1 affects the length and heterogeneity of human telomeres," Molecular Biology of the Cell, vol. 14, no. 12, pp. 5060-5068, 2003.

[44] B. Van Steensel and T. De Lange, "Control of telomere length by the human telomeric protein TRF1," Nature, vol. 385, no. 6618, pp. 740-743, 1997. 


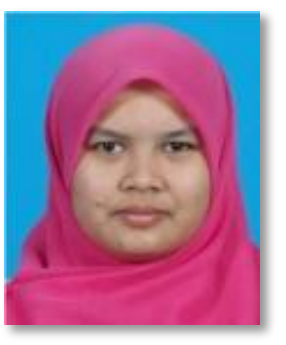

Norerlyda Hamdan was born in Tanjung Karang, June 2, 1987; graduated with Bachelor degree (Medical Laboratory Technology) from Universiti Teknologi MARA (UiTM) (Puncak Alam) and currently a student in Master of Medical Sciences (Physiology) programme at UiTM (Sungai Buloh Campus)

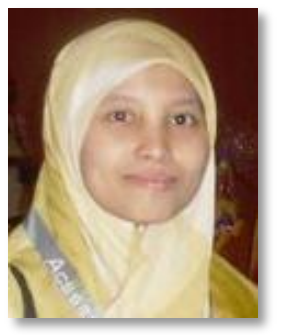

Nasibah Azme graduated with Bachelor (Medicine \& Surgery) degree from Al-Azhar University and Master (Medicine) at Universiti Teknologi MARA (Sungai Buloh). Currently, is pursuing her $\mathrm{PhD}$ at University of Western Australia. She is a medical lecturer at the Faculty of Medicine, UiTM (Sungai Buloh).

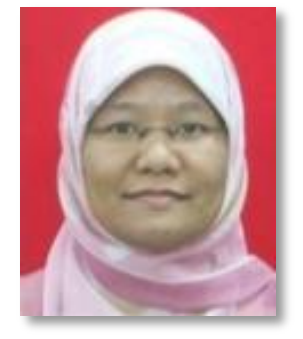

Mudiana Muhamad graduated with Bachelor (Biochemistry), Master (Biochemistry) and $\mathrm{PhD}$ (Molecular Biology) degrees from University of Malaya. She is a senior lecturer at the Faculty of Medicine, UiTM (Sungai Buloh).

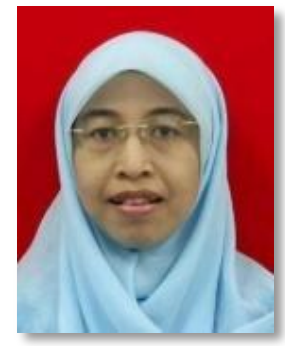

Nuraliza Abdul Satar graduated with Bachelor (Biomedical Science) and $\mathrm{PhD}$ (Physiology) degrees from Universiti Kebangsaan Malaysia. She is an Associate Professor in Physiology at the Faculty of Medicine, UiTM (Sungai Buloh). 